\title{
Misconduct Vs. Honest Errors: Should Honest Errors in Research be Punished?
}

\author{
Olukunle Cornelius Ewuoso* \\ Department of Philosophy, Stellenbosch University, South Africa
}

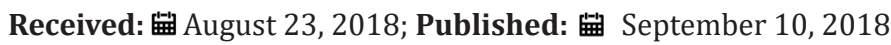

*Corresponding author: Olukunle Cornelius Ewuoso, Centre for Applied Ethics, Department of Philosophy, Stellenbosch University, Stellenbosch, Western Cape, South Africa

\begin{abstract}
No research endeavor is completely immune protected from errors. Errors are either intentional or unintentional. When they are intentional, they are called misconduct, while the contrary would be honest errors. Albeit errors in research have the potential of compromising the researcher's integrity, the work of other researchers or erode the trust of the public in researchers and research, it would still be improper to punish honest (unintentional) errors. I argued in this paper that honest errors should not be punished. For the reason that honest errors are not willful deliberate acts and punishing honest errors can trigger a mass hysteria in the research community. This could stifle research progress. In this review, I equally spell out a particular interpretation of African moral theory to support the thesis that honest mistakes, since they do not in anyway intend 'unfriendliness' on the part of the investigator, should not be punished. In the final section, I highlighted some measures which could be adopted to mitigate the occurrence of errors within the clinical context.
\end{abstract}

\section{Introduction}

The importance of maintaining scientific standards and integrity in research has been stated beyond all reasonable doubt. Bad research can waste time and resources, may unnecessarily expose the public to risks, slow the advancement of knowledge, and even undermine public trust in research, professional values and the integrity of research community. The above points correlate very well with the three-fold obligation of researchers; first, "researchers have obligation to honor the trust that their colleagues have reposed in them". As a cumulative enterprise, new research builds on previous knowledge. For this reason, an irresponsibly conducted research may send a whole enterprise in the wrong direction. Secondly, "researchers have obligation to themselves". An irresponsibly conducted research can have a deleterious effect on the researcher's integrity. Finally, "researchers have obligation to act in ways that serve the public good". The goal of research is to seek the truth; the truth which would impact positively on individual's wellbeing or lead to a reliable and valuable generalizable knowledge (National Academy of Sciences' Committee on Science Engineering and Public Policy, 2009). In summary, the researcher has an obligation to protect his/her integrity, the work of his colleagues and secure the trust of the public.

Albeit it is always important to maintain scientific standards in conducting research because of the above stated tripartite reasons, scientific endeavors are nevertheless, not completely protected from all errors. Researchers are human beings; even the most meticulous researcher is still susceptible to making errors.
The Merriam Webster Dictionary defines error as "the quality or state of erring" (2003). This, it continues, could be as a result of ignorance or imprudent deviation. In other words, some errors represent a willful departure from scientific standards and may be termed misconducts, while others are not directly intended, and are called honest errors. Misconduct, since it is a deliberate violation of acceptable scientific standards, should be punished. But when honest errors are made, and research is not immune to errors, should they be punished?

Existing literatures have answered the question whether honest errors should be punished in two ways: positive and negative. However, sufficient reasons to back their preferred position have not been satisfactorily articulated. This review article will attempt to fill this gap by highlighting intelligent reasons why honest mistakes - not misconduct - should not be punished. Specifically, I shall highlight a particular interpretation of an African (Ubuntu) moral theory to argue the thesis that honest mistakes since they do not constitute a willful attempt to jeopardize friendly relations, should not be punished. To achieve this study aim, I shall proceed in the first section to define and distinguish honest errors from misconduct. In the second section, I shall highlight reasons why honest errors should not be punished, as well as discuss ethical issues in misconduct and honest errors, after which I shall spell out a particular interpretation of an African moral theory for grounding my thesis that honest mistakes should not be punished. In the final analysis, I shall put forward some suggestions for reducing errors in research. 


\section{Conceptual Clarification}

Misconduct is defined in the US office of Science and technology Policy (issued by the Executive Office of the President) as "fabrication, falsification, or plagiarism in proposing, performing, or reviewing research, or in reporting research results" (quoted in Resnik and Stewart, 2012). To this definition, some also add any serious deviation from acceptable scientific norms which include but not limited to theft, destruction of data, damaging the research property of others with the intent to alter the research record or providing encouragement for others to do the same Adeleye and Adebamowo [1].

In other words, misconduct represents a clear case, either before, during or after research process, of the following;

a. Falsification (that is manipulating research process or changing data results)

b. Fabrication (which is making up data or results)

c. Plagiarism (which is stealing another's creation of the mind without due recognition)

d. Serious deviation from Scientific standards such as theft or destroying research data

e. Giving advice to others to fabricate or plagiarize.

In addition to the above, it is equally necessary that the researcher, who is accused of misconduct, knows what the crime is, intends the crime and voluntarily chooses it. Thus, knowledge, intentionality and voluntariness in choosing, distinguish misconduct from honest errors. Researcher, who is unaware of the offence and does not intentionally choose it, is not guilty of misconduct. He has only committed an error ignorantly. In other words, a key distinguishing factor between misconduct and honest errors is the intent to deceive. Hence, Resnik and Stewart [2] defined misconduct as first and foremost an intentional (or deliberate) deviation from accepted norms of scientific behavior. In other words, misconduct occurs when a researcher deliberately deceives either by falsifying, fabricating or plagiarizing, while this is not the case with honest error. For this reason, we may define honest error as an inadvertent mistake made by someone who has no direct intention of committing the offence. In the most part, the one who commits an error honestly, is not aware of the offence, and would readily change if the errors were disclosed to him.

\section{Honest Errors: To Punish or Not to Punish?}

In order for guilt to be established, and for punishment to be valid, Nigerian penal code provides that it must be proven beyond reasonable doubt that the offender is fully aware of the grave matter, the offender reflected on it and voluntarily chooses the grave matter. This understanding provides one theoretical framework for deciding whether honest error should be punished. In misconduct, as we argued in the previous section, there is an intention to deceive (by falsifying, fabricating or plagiarizing), the researcher is aware of this intention, and s/he willfully acts upon this intention. Hence, misconduct should be punished. However, in honest errors, an error has been committed no doubt. But this is not with the intention to deceive, and in the most part the researcher is unaware of it. Honest error, put simply, is an accident, which is an unavoidable event that could not have been foreseen by a reasonable person at the time the act took place.

The problem with punishing honest errors is that such punishment completely ignores the fact that no scientific endeavor is completely protected from errors. To punish all errors misconduct and honest mistakes - in scientific endeavors is to assume that science is perfect. Albeit this is the ideal, science in real life, is far from being perfect. Scientists are humans who are prone to making mistakes. Making mistakes is an inevitable part of growth. As a result, an honest mistake, which is unforeseen, should not be punished. Finally, punishing honest errors may also trigger a mass hysteria in scientific community. A situation, as Resnik and Stewart (2012) pointed out, whereby scientists may fear that they could be accused of misconduct for making a honest mistake or using novel methods or techniques, or proposing controversial theories or hypotheses Resnik and Stewart, 2012. Punishing honest mistakes will not remove the same from scientific enterprise. Contrarily, it may create an atmosphere of fear in the scientific community. And fear could negatively impact scientists' ability to think freely, creatively and innovatively. This will impede scientific growth and knowledge. Scientists who make mistakes stand a better chance to improve if they know they will not be punished for making mistakes. They (scientists) may be forced to start concealing or cover-up their mistakes if they realize that they will be punished for them. What would bring about scientific development is a safe environment where scientists can freely admit or report their mistakes. This can only be created if they(scientists) realize that they will not be punished in the same way deviant investigators are punished. In the next section, I will provide another ground to support the view that honest mistakes should not be punished. The ground I provide is a particular interpretation of an African (Ubuntu) moral theory.

\section{Honest Mistakes from an African Moral Theory}

The specific African moral philosophy which I propose here is Ubuntu philosophy. This philosophy is a genre of distinctive African ethics. A theory is to be considered 'African', Metz (2007a: 321) explains, if it is informed and defended by beliefs that are common among sub-Saharan African (Metz, 2007a: 321), thereby excluding Islamic Arabs in North Africa and White Afrikaners in South Africa. It is equally to be considered 'distinctive' insofar as it differs from what is dominant in contemporary Western society (Metz, 2007b: 375). It is a banality to describe African ethical theory as communitarian and Western ethical theory as individualistic. Community is a core ethical value amongst sub-Saharan Africans. Common amongst sub-Saharan Africans, Behrens [3] observes, is the belief that a person is a person through other persons. In other words, my humanity is inextricably linked or bound up with others. Metz [4] calls this Ubuntu. In his article, "Toward African Moral Theory" (2007a: 324), Metz affirms that Ubuntu is found across a wide array of sub-Saharan Africa, recur more often in literature on African ethics, and cuts across a long span of time Metz, 2011a: 532-558; from traditional societies to contemporary African intellectuals. 
Ubuntu is an essentially relational moral theory which grounds authentic personhood, as well as moral appropriateness or inappropriateness of an action in the extent to which it promotes harmonious relationships, ones in which individuals identify with others and care for others well-being. Albeit, identifying with others and caring for others well-being are conceptually distinct, the relational or communal character of Ubuntu, requires the combination of these two - 'identity' and 'solidarity'. The combination of these two is what called 'friendship' or 'love'. It is in this way that Ubuntu is described as essentially relational. In contrast to other Western ethical frameworks, such as principlism which makes no essential reference to 'others' but the given person, this African ethics requires individuals to interact harmoniously with others.

Relationality requires that relationships or properties of relationships, have moral primacy'. In light of this relational character, the basic reason why one ought not to engage in unfriendly acts appeals not to facts internal to an individual or the victim, but to facts about the way individuals interact. Specifically, unfriendly actions are intentional acts which tend to promote illwill and division. It is for this reason that unfriendly interactions are inappropriate way of relating, since they are not other-regarding. In light of this, defines right actions (based on this relational theory) "as right just insofar as it promotes shared identity among people grounded on good-will; an act is wrong to the extent that it fails to do so and tends to encourage the opposites, such as division and ill-will". On this account of right/wrong actions, deception, genocide, torture, slavery, rape, and human trafficking would be considered as instances of substantial unfriendliness directed at those who have themselves not acted this way. Based on this African moral theory, 'it would be wrong to act in an unfriendly way towards others, unless such unfriendly action was necessary to counter comparable unfriendliness on their part, or protect those threatened by their discordant/unfriendly behavior'. On the other hand, showing empathy, caring for others' well-being, relating communally, supporting each and so on, would be appropriate ways of exhibiting friendliness.

In light of the above, punishment is an unfriendly act, and is just insofar as it is necessary to counter/correct a comparable unfriendliness on the part of those who are punished. Hence, punishing misconduct would be just, since this is necessary to correct similar unfriendliness (intentional deviation from acceptable scientific standards) on their part. Honest mistakes, however, do not rise to the level of unfriendly acts, since they are unintentional and unavoidable events that could not have been foreseen by a reasonable person at the time the act took place. Hence, a comparable unfriendliness - such as punishing honest mistakes - on our part is not necessary, on this account of morally right action. Notwithstanding the proposal above, I admit that both misconduct and honest errors raise ethical concerns. In a study carried out by Adeleye and Adebamowo [5] 22.0\% of the 132 Nigerian medical/dental participants interviewed admitted to at least one of fabrication, falsification, and plagiarism. Others recognized that they may have committed them unknowingly.
Every error can significantly damage a scientist's integrity, compromise the work of research community and unnecessarily expose the public to risks. The 1996 Pfizer CSM Trovan trial, which led to preventable mortality in the Northern part of Nigeria is an example of adverse effects of errors, though arising from misconduct. The 1996 trovan study involved randomized trials: 98 patients on trovafloxacin and 100 patients on I.V ceftriaxone Okonta [6], Evuleocha [7]. Case fatality was $6 \%$ for ceftriaxone and 5\% for trovafloxacin (Wise, 2001). Some children developed physical and mental deformities Raufu [8]. Other participants denied knowing they were given adequate information regarding the risks involved. For this reason, they never provided a valid informed consent. Some claimants also insisted that several children were denied effective alternative treatment Chima [9] thus raising questions about standard of care.

Errors may also negatively impact the public's trust and confidence in science, violates moral precepts, or send scientific enterprise in the wrong direction. Errors also have the capacity to weaken self-regulation in science and erode the potential benefits of research (National Academy of Sciences' Committee on Science Engineering and Public Policy, 2009). Other additional negative impacts include loss or waste of data and resources; Institutions, individuals and even the research enterprise can suffer setbacks from errors, honest or real cases of misconduct, in research. These ethical issues perhaps explain the reason why some would argue that all errors should be punished. No doubt, in both misconduct and honest errors, someone is led to disbelieve something that is actually true or to believe something that is actually false Schneider and Schuklenk [10]. But punishing all errors would not free science from the same. Contrarily, it may stifle science of development and progress, since scientists would no longer be able to express themselves freely.

I equally agree that it may be extremely difficult to distinguish between misconduct and honest errors, since as argued in previous paragraphs; one must evaluate a person's intentions in order to reach this sound judgment. For example, Section S(6) of Nigerian's National Code of Health Research Ethics (2007) requires investigators to promptly investigate and report 'all' adverse event to the sponsor and/or Institutional Review Board or the Ethics Committee. An investigator may fail to include an adverse event in his report and claim that it was an honest error without any intent to deceive his/her sponsor or Institutional Review Board. It may be difficult for the review board or Ethics Committee to judge whether the investigator is telling the truth, since the committee may not have access to the individual's subconscious state, or confidently judge their secret intentions to determine whether this was indeed an unfriendly behavior on the part of the researcher, as well as whether this unfriendliness would require a comparable unfriendliness - such as suspension of research project or an outright revocation of ethical approval - on the part of the institutional (review) board.

For making this judgment, I shall suggest that if reviewers or board members were to point out his/her mistakes to the scientist, and the scientist corrects the mistake and thanks the reviewers or 
board members, then this would seem to be an honest mistake. But, if the reviewer points this error to the researcher, and the researcher refuses to acknowledge it, this would appear to be a deliberate misbehavior and should be taken as a deliberate act of unfriendliness and thus, punished since - following Ubuntu philosophy which I articulated above this form of unfriendliness on the part of the investigator requires a comparable unfriendliness on our part to counter the same. Finally, errors honest mistakes and misconduct could be mitigated in research. In the subsequent section, I shall articulate different measures which may be adopted to mitigate errors in research.

\section{Recommendations for Mitigating Errors in Research}

The goal of research is to contribute to the vast repertoire of knowledge. Traditional definition of knowledge defines knowledge as a justified true belief Cohen [11], Nagel [12]. Truth is opposed to falsehood. The primary interface of mitigating errors in research is at the investigator's/researcher's level. The researchers must be as honest as humanly possible. Scientists may be in error, research may be incomplete, data may mislead, but researchers must be encouraged to be open to receive corrections, maintain transparency, be objective and honest in proposing, performing, or reviewing research, or in reporting research results. They must attempt to carefully review research for errors. They are to use resources wisely and avoid waste. Funding agencies and publishing journals can play key roles in reducing errors in research. Funding agencies are to insist that good research principles are followed by researchers, and publishers should carefully review studies that are submitted to them by researchers, for research errors. Institutions also have a role to play in reducing errors in research [13-20].

They should increase oversight function of research and ensure that a system which emphasizes excellence, trustworthiness, as well as discourages lawlessness in the conduct of research, is put in place. This system should incorporate administrative regulation of research to ensure compliance with local and international standards. Institutions should also put in place structures that would promote best practices in research, as well as make provision for detecting, reporting, and investigating errors in research [21-26]. They also have a special responsibility for training young researchers and students in good research citizenship. Finally, institutions and researchers must maintain adequate record-keeping habits, which emphasize legibility, accuracy, completeness, and orderliness of records in a manner that makes them reproducible.

\section{Conclusion}

I set out at the beginning of this paper to answer the question; "Should honest errors in research be punished?" This question was answered in the negative. I defined error as the quality or state of erring. This could be intentional or unintentional. When it is intentional, it is misconduct, while unintentional is honest mistake. I also provided reasons why honest errors should not be punished. I argued in this paper that honest errors are not willful actions aimed at intentionally violating existing scientific standards. In this regard, they (honest mistakes) are not unfriendly actions which require a comparable unfriendliness (such as punishing such mistakes) on your part. In the most part, the researchers are unaware of their actions and would correct their mistakes if they were pointed out to them. Furthermore, I argued that punishing errors may trigger mass hysteria which could stifle scientific progress. Finally, I argued that honest errors, as well as intentional errors, could be mitigated if researchers are encouraged to embrace professionalism, transparency, honesty and objectivity in proposing, performing, or reviewing research, or in reporting research results.

\section{References}

1. Adeleye OA, Adebamowo (2012) Factors associated with research wrongdoing in Nigeria. J Empir Res Hum Res Ethics 7: 15-24.

2. behrens KG (2013) Towards an Indigenous African Bioethics. The South African Journal of Bioethics and Law 6: 32-35.

3. Chima SC (2006) Regulation of biomedical research in Africa. BMJ 332: 848-51.

4. Cohen S (2011) The Gettier Problem in informed consent. J Med Ethics 37: $642-5$

5. Dahanukar N, Molur S (2012) Scientific Conduct and Misconduct: Honesty is still the Best Policy. Journal of Threatened Taxa 4: 2845-2848.

6. Interdisciplinary Journal of Evuleocha S (2012) The Global Market in Human Experimentation: Pfizer and the Meningitis Experiment in Research in Business 2: 46-55.

7. Thaddeus Metz (2007) Toward an African Moral Theory. The Journal of Political Philosophy 15: 321-341.

8. Thaddeus Metz (2007) Ubuntu as a Moral Theory: Reply to Four Critics. South African Journal of Philosophy 26: 369-388.

9. Thaddeus Metz (2007) Ubuntu as a Moral Theory: Reply to Four Critics. South African Journal of Philosophy 26: 369-387.

10. Thaddeus Metz (2008) Respect for persons permits prioritizing treatment for HIV/AIDS. Dev World Bioeth 8: 89-103.

11. Thaddeus Metz (2010) African and Western moral theories in a bioethical context. Dev World Bioeth 10: 49-58.

12. Thaddeus Metz (2010) African and Western Moral Theories in Bioethical Context. Dev World Bioeth 10: 49-58.

13. Thaddeus Metz (2010) An African theory of bioethics: reply to MacPherson and Macklin. Dev World Bioet 10: 158-163.

14. Thaddeus Metz (2011) Ubuntu as a Moral Theory in South Africa. African Human Rights Law Journal 11: 532-559

15. Thaddeus Metz (2011) Ubuntu as Moral Theory and Human rights in South Africa. African Human Rights Law Journal 11: 532-559.

16. Thaddeus Metz (2011) An African Theory of Moral Status: A Relational Alternative to Individualism and Holism. Ethical Theory and Moral Practice 15: 387-402.

17. Thaddeus Metz (2017) A Bioethic of Communion: Beyond Care and the Four Principles with regard to Reproductino. In: Soniewicka M (Eds.). The Ethics of Reproductive Genetics - Between Utility, Principles and Virtues. Springer International Publishing AG.

18. Nagel J, Juan VS, Mar RA (2013) Lay denial of knowledge for justified true beliefs. Cognition 129: 652-661.

19. National Academy of Sciences' Committee on Science Engineering and Public POLICY, N. A. O. E. U. A. I. O. M. U. 2009. On Being a Scientist: A Guide to Responsible Conduct in Research, Waschington (DC), National Academies Press (US).

20. Ogundele S, Falade CO (2006) Good Clinical Practice in Nigeria-The Way Forward. Annals of Ibadan Postgraduate Medicine 4: 28-32.

21. Okonta PI (2014) Ethics of clinical trials in Nigeria. Niger Med J 55: 188194. 
22. Raufu A (2003) Nigerians in drug trial take their case to US court BM pp. 326- 899.

23. Resnik DB, Stewart CN JR (2012) Misconduct versus honest error and scientific disagreement. Account Res 19: 56-63.

24. Schneider B, Schuklenk U (2005) Module six: special issues. Dev World Bioeth 5: 92-108.

ISSN: 2574-1241

DOI: $10.26717 / B J S T R .2018 .08 .001715$

Olukunle Cornelius Ewuoso. Biomed J Sci \& Tech Res

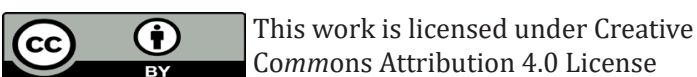

Submission Link: https://biomedres.us/submit-manuscript.php
25. Weed D (2003) Preventing Scientific Misconduct. In: Emanuel Ej, Crouch Ra, Arras Jd, Moreno Jd Grady C (Eds.). Ethical and Regulatory Aspects of Clinical Research. Baltimore: Johns Hopkins University Press.

26. Wise J (2001) Pfizer accused of testing new drug without ethical approval BMJ 322: 194.

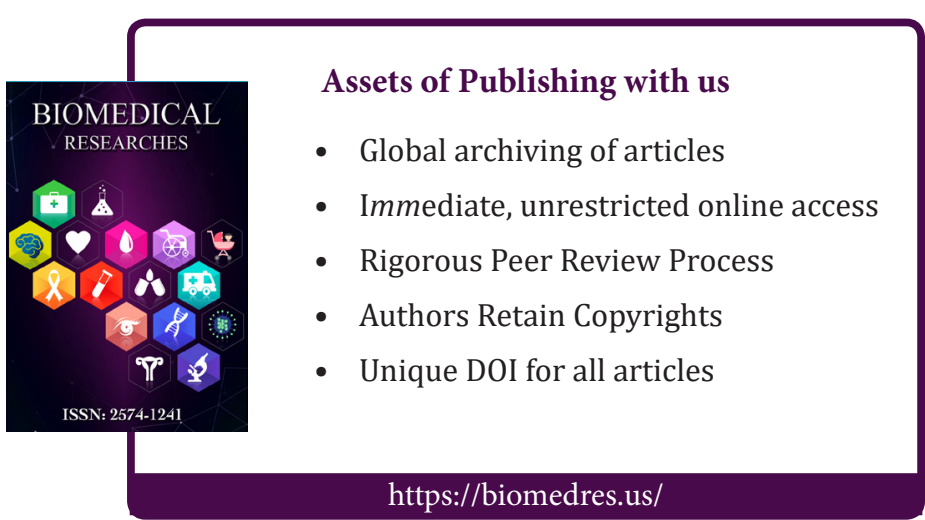

